
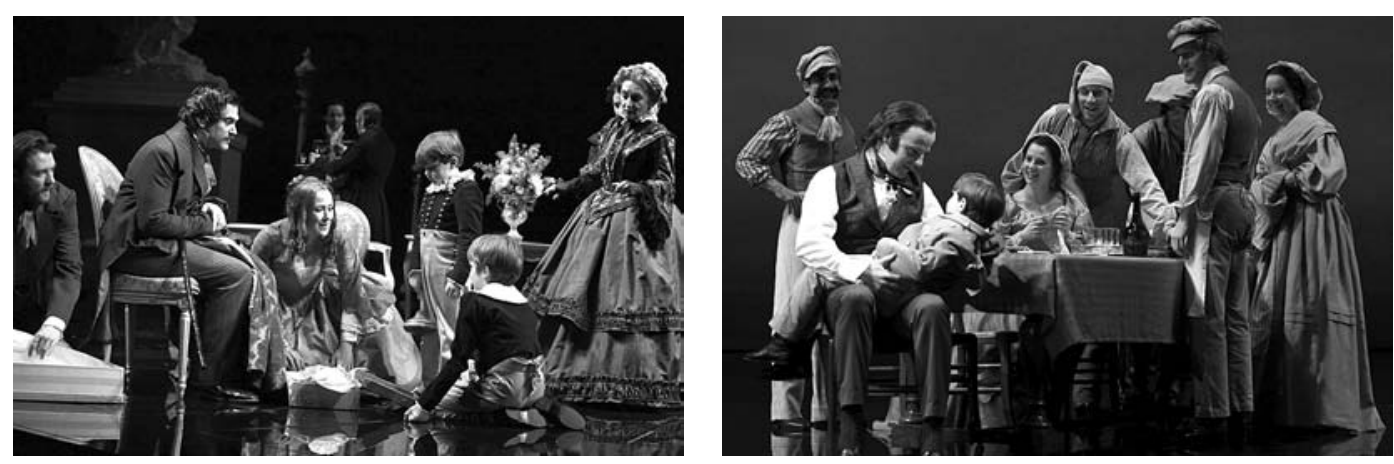

The Coast of Utopia, de Tom Stoppard, enc. Jack O'Brien, cenografia de Bob Crowley e Scott Pask, figurinos de Catherine Zuber, Lincoln Center Theater, 2006, fot. Paul Kolnik.

\title{
Cenografia e peso teatral
}

\author{
Steve Capra
}

Quando Inigo Jones introduziu o perspectivismo na cenografia inglesa por influência da Europa continental no séc. XVII, o dramaturgo Ben Jonson lamentou o facto de o espectáculo estar a sobrepor-se à poesia. Hoje em dia, precisamos de questionar a relação entre a cenografia e os outros elementos do teatro. Ao referirmos as qualidades que queremos na cenografia, temos de começar por perguntar que importância queremos que a cenografia tenha no espectáculo. Como é que o peso da cenografia se relaciona com o texto?

\section{Espectáculo incarnado}

São bem conhecidas algumas cenografias pesadas que constituiam o elemento dominante dos espectáculos para que tinham sido criadas. A cenografia de John Napier para Gatos (Cats) é um exemplo, assim como a de Maria Björnson para 0 fantasma da ópera. Para examinarmos outras cenografias de peso, comecemos com os cenários concebidos para a produção de Turandot na Ópera Metropolitana (Met) de Nova lorque em 1987. 0 New York Times chamou-Ihe o "espectáculo incarnado" (26 de Setembro de 2002).

Extraordinariamente impositivo, o cenário estava perfeitamente adequado ao material. É, primeiro que tudo, uma coisa em grande escala. Consideremos as dimensões do palco do Met: o proscénio tem 16 metros e meio de largura e de altura; a distância entre a cortina e o fundo do palco principal é cerca de 24 metros e meio, a altura do palco até à teia é cerca de 33 metros e meio. A produção tinha um elenco de 286 artistas (o auditório tem 4 mil lugares). Apesar da sua extravagância, o cenário não se sobrepunha à produção. Afinal, a ópera foi concebida como uma amálgama de artes. Além disso, de todos os elementos aristotélicos do drama, a música aqui é o elemento dominante. 0 cenário não pode sobrepor-se a ela e, seguramente, não se pode sobrepor à fortíssima partitura.

\section{A cenografia acima do drama}

Por oposição, pensemos na recente produção da trilogia de Tom Stoppard - A costa da utopia (The Coast of Utopia, 2006, 2007) - no Centro Lincoln para as Artes do Espectáculo (em Nova lorque). Esta produção custou 7 milhões de dólares e ganhou um número recorde de
Prémios Tony. Os cenógrafos - Bob Crowley e Scott Pask - ofereciam uma série assombrosa de imagens evocativas. Enquanto a cena era o lugar da nobreza, cerca de trinta serviçais, de cara tapada, estavam de pé - parados - por detrás de uma cortina de gaze. Quando a cena se passa em Moscovo, fica visível um Kremlin de um cristalino brilhante suspenso por detrás do telão em rede, com as suas graciosas torres em forma de cebola. Evoca-se o pôrdo-sol, uma belíssima lua cheia reflecte-se no chão do palco e vêem-se superficies planas da maré na ilha de Wight - domina a cor cinza, com aquela textura extraordinária e macia.

Tudo somado, foi um triunfo do cenário sobre o drama. 0 público e os críticos ficaram tão impressionados pelo cenário que não conseguiram aplicar as exigências dramatúrgicas ao texto, a que faltava estrutura e que tinha outros erros elementares. De facto, se as peças tivessem sido apresentadas num pequeno teatro da offoff-Broadway, não teriam atraído a atenção dos críticos e muito menos a sua aprovação.

A integridade estrutural para suportar o peso visual Robert Wilson é um dos cenógrafos e encenadores mais importantes da América, e o seu trabalho é invariavelmente impressionante. Os seus cenários para a peça Woyzeck (2000, no teatro Betty Nansen em Copenhaga), baseada na peça de Büchner, tinham um peso enorme, eram muito influenciados pelo expressionismo, com portadas assimétricas e focos de luz isolados. Adaptavam-se perfeitamente aos materiais e combinavam bem com os outros elementos da produção no sentido de criarem um espectáculo de teatro indivisivel e poderoso. É evidente que o êxito se reflecte na natureza da obra. Além disso, nota-se que a peça de Büchner é enxuta e directa, e tem uma tremenda força dramática.

Os cenários de Wilson para o Peer Gynt, de Ibsen (2005, co-produção do Teatro Nacional de Bergen e do Teatro Norueguês de Oslo) são igualmente idiossincráticos e vigorosos. Revelam a focalização característica de Wilson em pormenores seleccionados, descurando muitas outras coisas. Um enorme candelabro está suspenso da teia, desligado de qualquer tecto ou paredes. Fortemente iluminado no seu fato branco, Peer sozinho atrai toda a nossa atenção.
Steve Capra

é membro do Comité Internacional da

Associação Americana de Críticos de Teatro, tem escrito sobre teatro para várias publicações e é autor do livro Theater Voices, que reúne uma série de entrevistas a criadores de teatro da América, Inglaterra e Rússia. Tem participado em júris de prémios de escrita teatral e é autor de adaptações para o palco e rádio. Actualmente trabalha em Nova lorque com o Living Theatre. 


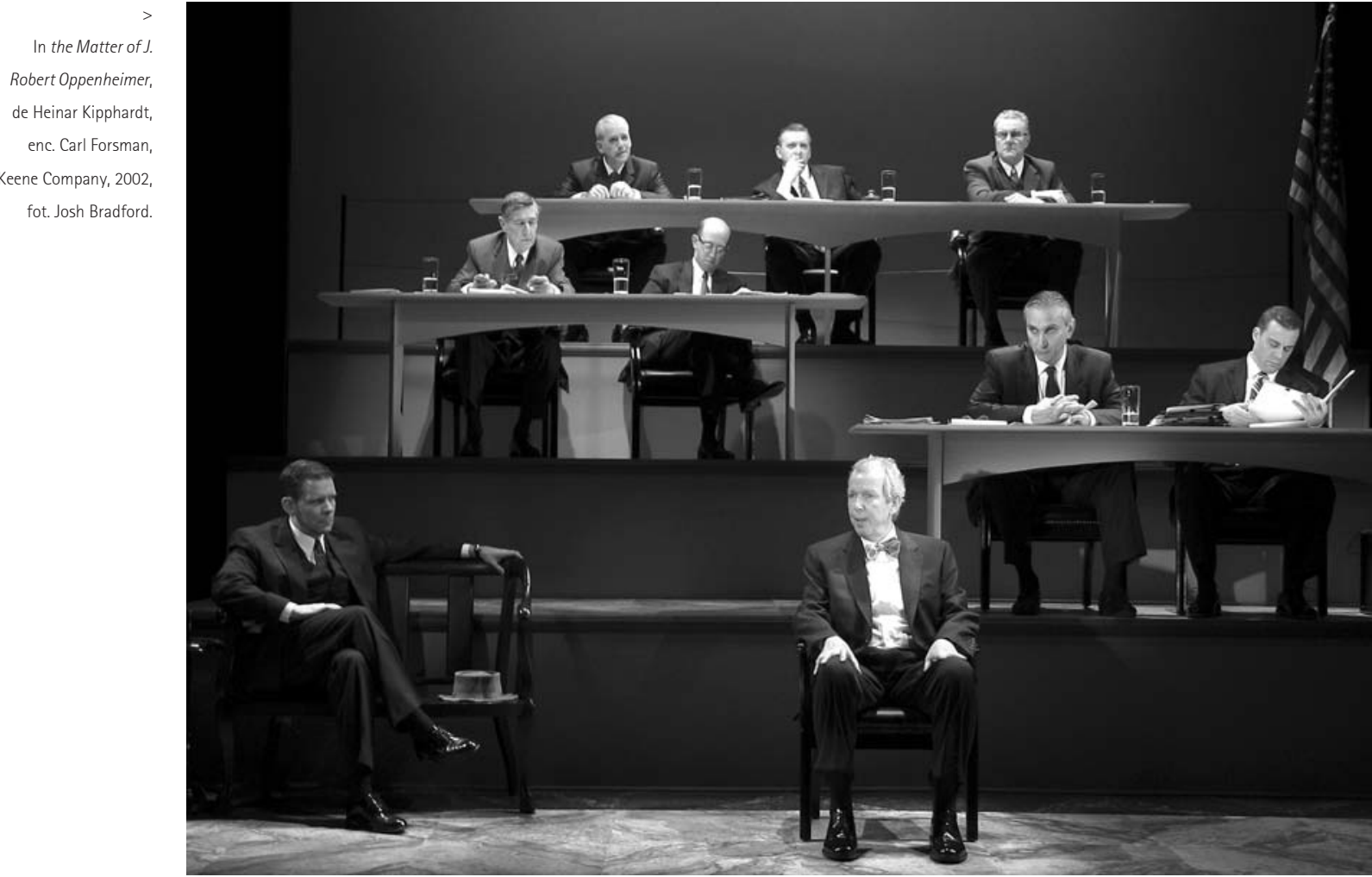

As imagens funcionavam perfeitamente na primeira parte da peça, mas na segunda, sobrepunham-se à acção. A verdadeira diferença vem da estrutura da peça que começa com a promessa de uma linha forte e dura, mas perde a compressão dramática na segunda parte à medida que a sua personagem principal vai progressivamente perdendo o seu rumo e objectivo. Desta forma, perde a integridade estrutural para adquirir peso visual.

\section{Um elemento vivo do cenário}

Falando de outro cenógrafo e encenador: os cenários de Richard Foreman para as suas próprias peças no Teatro Histérico-Ontológico (The Ontological-Hysteric Theater), de Nova lorque, desempenham um papel diferente na produção. São concebidos na génese do processo criativo, inseparáve do diálogo indizivel de Foreman, e criam uma espécie de alucinação cénica. Torna-se desordenado e eclético. Uma parede plástica transparente separa os actores do público, mas cordas esticadas horizontalmente pela sala - no sentido da sua profundidade e largura - ligam palco e plateia.

Os cenários - e as produções - têm um enorme êxito e transmitem-nos um inexplicável sentimento de frescura. Mas a visão de Foreman altera a função tradicional dos actores. Aqui eles tornam-se um elemento vivo do cenário.

\section{Teatro ao ar livre}

É importante considerar o teatro ao ar livre na sua relação com o cenário. No Festival de Shakespeare em Nova lorque, a produção de A gaivota (2001) servia-se de um cenário de Bob Crowley que explorava a folhagem e a topografia do Central Park. Os troncos de bétulas no palco estendiamse até às árvores no parque. Uma representação deste pano de fundo num proscénio tem todas as probabilidades de se sobrepor ao diálogo delicado de Tchekov. É um reflexo profundo do nosso sentido da natureza o facto de o mundo real nunca o fazer, e a encenação ter sido soberba.

\section{0 actor como marioneta}

Os cenários de Lee Breuer para a produção dos Mabou Mines (de Nova lorque) de As bagas vermelhas (The Red Beads, 2005) revelam uma preocupação com o teatro como um espaço a duas dimensões. São deslumbrantes e adequados ao material, uma fábula. Num palco nu, tecidos de todos os tamanhos servem para representar coisas, estados de espírito, pensamentos - animados por "leques" eléctricos ou ventoinhas. As notas do encenador chamam a isto "marionetas de vento" e são concebidas pelo mestre em marionetas Basil Twist. Os actores, integrados no cenário, muitas vezes flutuavam pelo palco. Estavam reduzidos a marionetas. Há uma diferença entre o intérprete que simplesmente se integra num cenário pintado e o intérprete que tem consciência do seu próprio trabalho.

\section{Nenhuma pretensão à simples beleza}

Os cenários da Companhia Keen (de Nova lorque) para o espectáculo Na questão de J. Robert Oppenheimer (In the Matter of J. Robert Oppenheimer, 2006), desenhados por Nathan Heverin, reflectem o carácter intelectual e nada sentimental do texto. 0 cenário é uma sala de tribunal. Os actores, de frente para a plateia, sentavam-se em carteiras arrumadas em quatro filas sobre estrados em cima do palco, com Oppenheimer (o sujeito alvo do julgamento) sentado sozinho ao nivel no palco. Aquelas três filas que se erguiam acima do indivíduo exprimiam a opressão pesada do governo, enquanto os fatos cinzentos sobre o pano de fundo cinzento e liso reflectiam a repressão desse período. Praticamente não havia movimento no palco. Este conjunto severo e que sinalizava as limitações de então chamava a nossa atenção para os actores, talvez porque o cenário não reclamava para si a simples beleza.

A mulher besuntada de chocolate

Karen Finley, uma das mais destacadas artistas de 


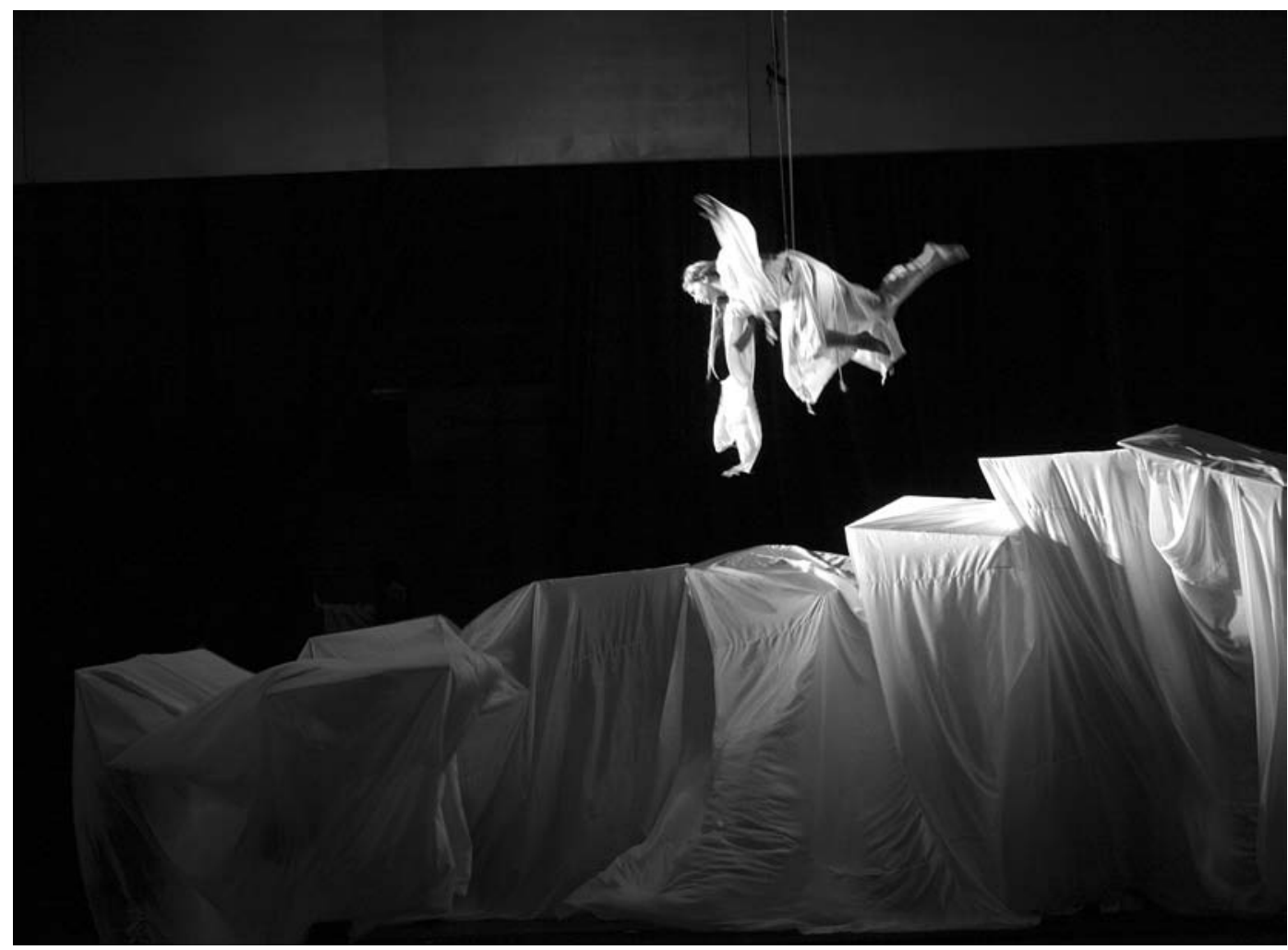

performance da América, actua num palco nu ou quase $n u$, muitas vezes sem roupa alguma. Em alguns espectáculos, ela besuntou o seu corpo nu com chocolate. Por causa desse tipo de espectáculos, foi-Ihe retirado o apoio estatal em 1990. Ela pôs em causa a decisão, e o caso (que envolvia também outros artistas) tornou-se tremendamente célebre. Uma forma de reconhecer o teatro importante é ver o que é proibido.

Será que Finley teria criado uma tal sensação de escândalo se estivesse nua no cenário do Met para a ópera Turandot? Duvido. Mesmo se todo o coro estivesse nu nesse cenário, isso não teria atingido a nossa consciência de forma tão viva.

\section{Pobreza de meios}

Em 1972, Julian Beck escreveu:

Se o cenário não consegue dizer ao espectador o que um palco nu pode fazer melhor, não o façam: a ornamentação supérflua distrai a atenção do que é central. Muitos dos costumes e moralidade da classe média são ornamentos destinados a distrair a nossa concentração do que é central nas coisas... Temos de trabalhar com a pobreza de meios, porque é com a pobreza de meios que temos de enfrentar os poderes dominantes. (Beck 1972)

Beck, que criou o Living Theatre em Nova lorque com Judith Malina, concebeu o cenário para A prisão (The Brig), em 1967. Nesse ano foi adaptado a um novo espaço por Gary Brackett. Era compulsivo na sua simetria e nas linhas direitas. A cena era uma prisão militar. 0 público olhava através de uma rede de arame farpado, de um muro de pedras, e depois através de uma cerca de elos de corrente. 0 resultado era um cenário opressivo que não comprometia a importância central do actor. 0 actor tornava-se objecto da opressão, e nós reconheciamos a sua humanidade.

\section{Compromisso físico}

É missão singular do teatro moderno tratar de assuntos sociais. Ibsen e Brecht ensinaram-nos isso. A razão é que a força decisiva do teatro é mostrar como vivemos juntos. Quando o meio de representação se torna artificial, com um cenário inventado, estabelece-se uma separação entre o actor e o público, entre a peça e a sociedade. Um dos desenvolvimentos mais importantes do teatro do século $X X$ foi o regresso ao compromisso físico com a sociedade.

Eu proponho que se o público deve relacionar a peça com a sua vida, talvez não devêssemos usar cenário algum, nem sequer representar dentro de um edifício. A prisão foi representada este ano num passeio em Nova lorque, na praça Times Square, apresentada exactamente como uma produção do Living Theatre contra a guerra, Não senhor (No, Sir), ao lado de outras produções. A companhia representou diante de um centro de recrutamento militar. Era impossivel não perceber o que estava em causa. De facto, os actores foram por diversas vezes assediados pela polícia de Nova lorque. Outra forma de distinguir o bom teatro é a atenção da polícia.

Vemos, portanto, que o próprio peso do cenário tem uma importância fundamental para o espectáculo. 0 seu grau de centralidade para a peça de teatro, bem como a relação entre o cenário e o texto, são questões delicadas. Temos de estar atentos ao poder do cenário para dominar e o que está envolvido nesse poder. Temos de ter a certeza de que a declaração artística que faz é justamente a que queremos fazer.

\section{Referência bibliográfica}

BECK, Julien (1972), The Life of the Theatre, City Lights Book.

Tradução de Maria Helena Serôdio 